\title{
Assessment of longitudinal changes in strain using DENSE in patients with myocardial infarction
} Christie McComb ${ }^{1,2 *}$, David Carrick ${ }^{3}$, Rosemary Woodward ${ }^{4}$, John D McClure ${ }^{1}$, Aleksandra Radjenovic ${ }^{1}$,
John Foster ${ }^{1,2}$, Colin Berry

From 17th Annual SCMR Scientific Sessions

New Orleans, LA, USA. 16-19 January 2014

\section{Background}

Myocardial infarction (MI) causes contractile dysfunction in the affected tissue, which can be assessed by using DENSE (Displacement ENcoding with Stimulated Echoes) to quantify myocardial strain[1,2]. The aim of this study was to investigate changes in strain revealed by DENSE between the occurrence of MI and a 6 month follow-up, and the relationships with other clinical measures.

\section{Methods}

50 male patients (age $56 \pm 10$ years) underwent CMR on a 1.5T Siemens Avanto within 7 days of MI, and 47 returned for a follow-up scan after 6 months. The protocol included cine, DENSE (2D) and late gadolinium enhancement (LGE) imaging. Cine images were used to assess cardiac function by calculating LV ejection fraction (LVEF) and end-systolic volume (LVESV). DENSE and LGE were compared using a single mid-ventricular short-axis slice, which was analysed both as a whole slice and after division into 6 AHA segments. The percentage of each segment which contained LGE was calculated using a threshold of mean $+5 \mathrm{SD}$ of remote myocardium intensity. DENSE images were analysed to obtain a value for peak circumferential strain (Ecc). Segments in the baseline scans were grouped according to the extent of LGE (non-infarcted, $<50 \%$ infarcted, $>50 \%$ infarcted), and the change in peak Ecc between baseline and follow-up was evaluated using a oneway ANOVA with Tukey's post-hoc test. Individual patients were compared directly, and the correlations between change in strain and (i) change in LGE (segments) and (ii) change in cardiac function (slices) were assessed.

\section{Results}

Diagnostic images were obtained for 50 patients at baseline, and for 43 patients at follow-up. The results of the group comparisons and the individual patient comparisons are illustrated in Figure 1 and Figure 2 respectively.

\section{Conclusions}

Strain recovery was disclosed by DENSE in infarcted tissue at 6 months post-MI. An increase in peak Ecc at follow-up is associated with a reduction in LGE, and improvement in

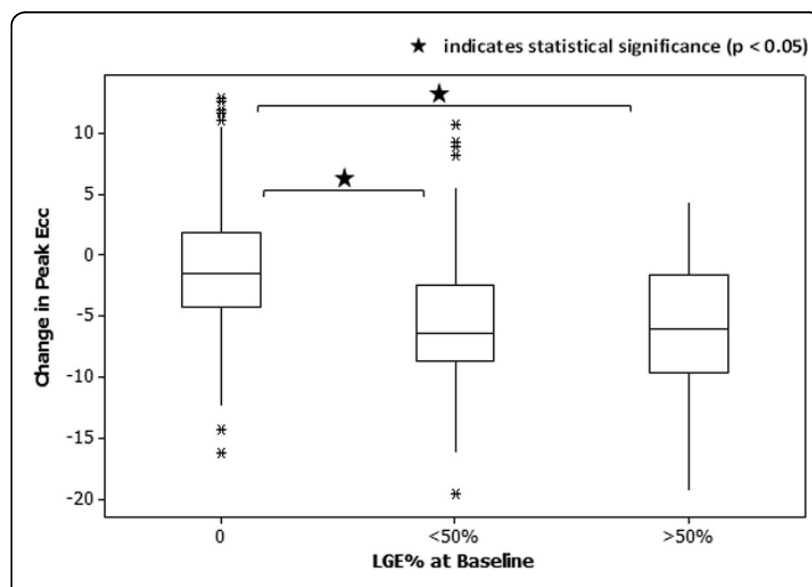

Figure 1

'BHF Glasgow Cardiovascular Research Centre, Glasgow, UK

Full list of author information is available at the end of the article 

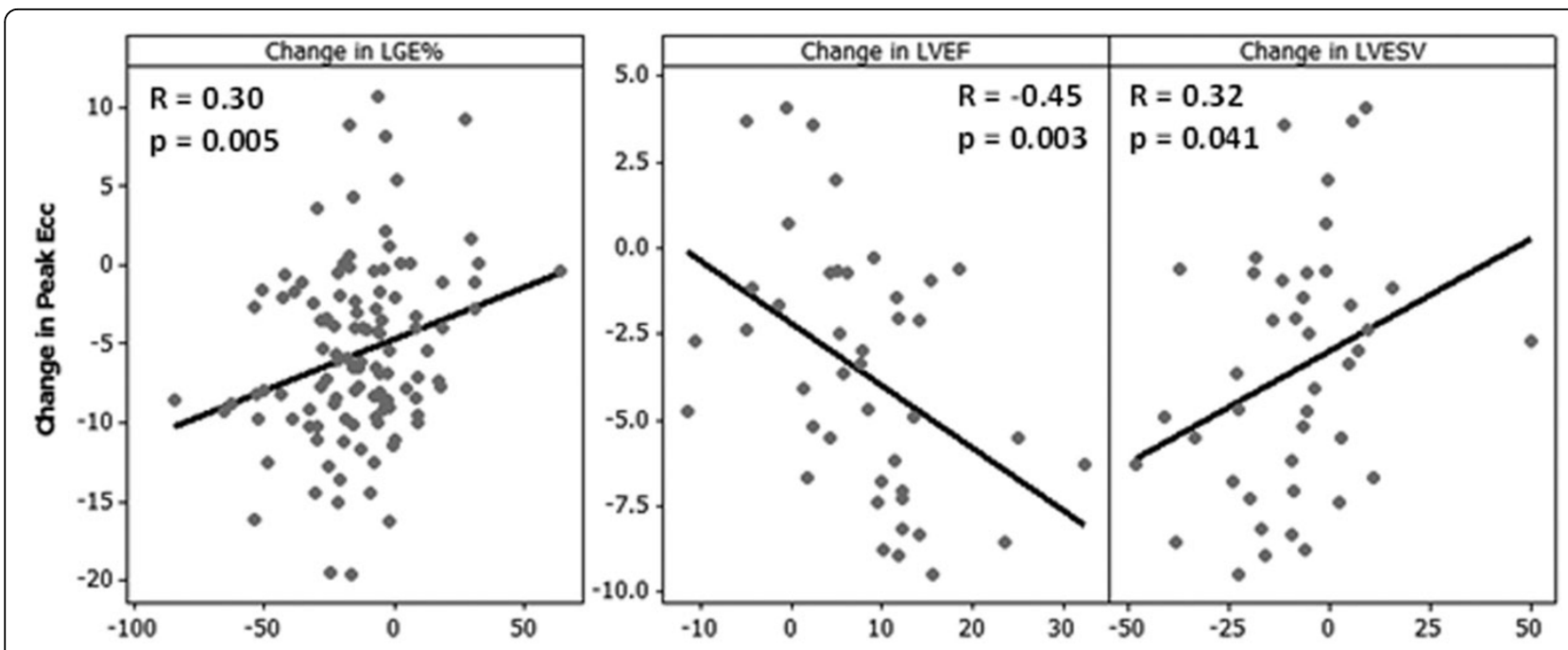

Figure 2

LVEF and LVESV. Further work is required to take infarction in adjacent segments and slices into account, as this may provide a more precise insight into the relationship between myocardial strain, LGE and cardiac function.

\section{Funding}

N/A.

\section{Authors' details}

'BHF Glasgow Cardiovascular Research Centre, Glasgow, UK. ${ }^{2}$ Clinical Physics, NHS Greater Glasgow and Clyde, Glasgow, UK. ${ }^{3}$ Cardiology, Golden Jubilee National Hospital, Glasgow, UK. ${ }^{4}$ MRI, Golden Jubilee National Hospital,

Glasgow, UK.

Published: 16 January 2014

\section{References}

1. J Magn Reson 1999, 137:24-252.

2. Magn Reson Med 2012, 67:1590-1599.

\section{doi:10.1186/1532-429X-16-S1-P187}

Cite this article as: McComb et al:: Assessment of longitudinal changes in strain using DENSE in patients with myocardial infarction. Journal of Cardiovascular Magnetic Resonance 2014 16(Suppl 1):P187.

Submit your next manuscript to BioMed Central and take full advantage of:

- Convenient online submission

- Thorough peer review

- No space constraints or color figure charges

- Immediate publication on acceptance

- Inclusion in PubMed, CAS, Scopus and Google Scholar

- Research which is freely available for redistribution 